\title{
Examining the Use of Hofstede's Uncertainty Avoidance Construct as a Definition or Brief Comparison in Ethics Research
}

\author{
Julia D. Davis ${ }^{1}$, Richard A. Bernardi ${ }^{1}$ \& Susan M. Bosco ${ }^{1}$ \\ ${ }^{1}$ Gabelli School of Business, Roger Williams University, Bristol, Rhode Island, USA \\ Correspondence: Richard A. Bernardi, Gabelli School of Business, Roger Williams University, Bristol, Rhode \\ Island, USA. E-mail: rbernardi@rwu.edu
}

Received: June 5, 2012

Accepted: June 21, 2012 Online Published: August 8, 2012

doi:10.5539/ibr.v5n9p49

URL: http://dx.doi.org/10.5539/ibr.v5n9p49

\begin{abstract}
This research focuses on studies in the Journal of Business Ethics (hereafter JoBE) that used Hofstede's uncertainty avoidance construct. The JoBE is the foremost outlet for ethics research for most academic disciplines. We included research from the International Journal of Value Based Management (hereafter $I J o V B M$ ) and Teaching Business Ethics (hereafter TBE), which merged with the JoBE in 2004. There were 84 studies that used Hofstede's uncertainty avoidance construct as a definition or brief comparison. Understanding how uncertainty avoidance has already been used could provide opportunities for future research to further increase our understanding of differences in international behavior and/or perceptions.
\end{abstract}

Keywords: Hofstede, ethics, uncertainty avoidance

\section{Introduction}

This research examines the use of Hofstede's cultural construct of uncertainty avoidance (hereafter UA) in international ethics research; however, while we only report on Hofstede's UA construct, the majority of the research we examined in this study included all of Hofstede's constructs. UA is a surrogate for a society's relative willingness to tolerate ambiguous outcomes. Hofstede's $(1991,150)$ UA construct was calculated as the combined score for a series of three questions dealing with: rules orientation, employment stability, and nervousness or stress at work. Rules orientation examines the rigidity of an individual's beliefs about following rules: "Company rules should not be broken - even if the employee thinks it is in the company's best interests" (150). The employment stability factor reflects the anticipated tenure for the individual's current job: "How long do you think you will continue working for this company?" (150). The stress-at-work factor reflects individuals' responses to the statement: "How often do you feel nervous or tense at work?" (150). Hofstede (150) defined culture as a "set of likely reactions of citizens with a common mental programming. . . . reactions need not be found within the same persons, but only statistically more often in the same society". Consequently, Hofstede's UA construct is the average of the combined scores (Formula 1) of all individuals from each country.

$$
\mathrm{UA}=300-30 \text { (rule orientation) }- \text { (\% intending to stay less than } 5 \mathrm{yrs})-40 \text { (stress score) }
$$

The uses of Hofstede's cultural dimension of UA vary in the JoBE as well as in the IJoVBM and TBE. In this paper those varied uses are identified by distinct categories, which allows readers to quickly search and understand what information is available in these journals. In the process of our review, we grouped articles into two categories that differentially use UA - definitional and brief comparisons. With respect to the association between these articles and ethics research, those in our definition category briefly mention UA as part of Hofstede's (1980) original research and do not link to ethics research. Brief comparison articles attempt to describe differences between countries and some of these address ethics topics.

\section{Methodology}

The first step in the data gathering process was to identify articles to examine from the JoBE, which has been published since 1982. We began by using the journal's online search function for 'UA'. To ensure that we identified all articles, we also used Google's Advanced Scholar searching for 'UA' in the JoBE. We included only original journal articles; book reviews, comments, discussions and rejoinders were not included in our analysis. While this journal has been published since 1982, the first use of Hofstede's UA construct was in 1990; so our study actually includes articles from 1990 through 2011 (e.g., a 22-year period). While we searched all 
volumes of the journal between 1982 and 2011, we found our first article using UA in 1990; consequently, we refer to this research as a 22-year study.

While our primary aim was to include articles from the $J o B E$, the publisher of this journal also published the IJoVBM from 1988 through 2003 and TBE from 1997 through 2003. These journals were 'merged into the JoBE' at the beginning of 2004. We submit that article counts in the JoBE between 1988 and 2003 (i.e., when these journals were independently published) would be understated compared to other years if these journals were not considered in the article count. Consequently, our total article count and classifications include publications from the IJoVBM and TBE. After identifying the articles that included Hofstede's UA, the second step in the data gathering process was to determine how UA was used in each article. We classified the 84 articles as either definition or brief comparisons. After classifying the articles, we subsequently reviewed the classifications for validation purposes and resolved any classification differences.

Panel A: Growth in the use of UA in international ethics research

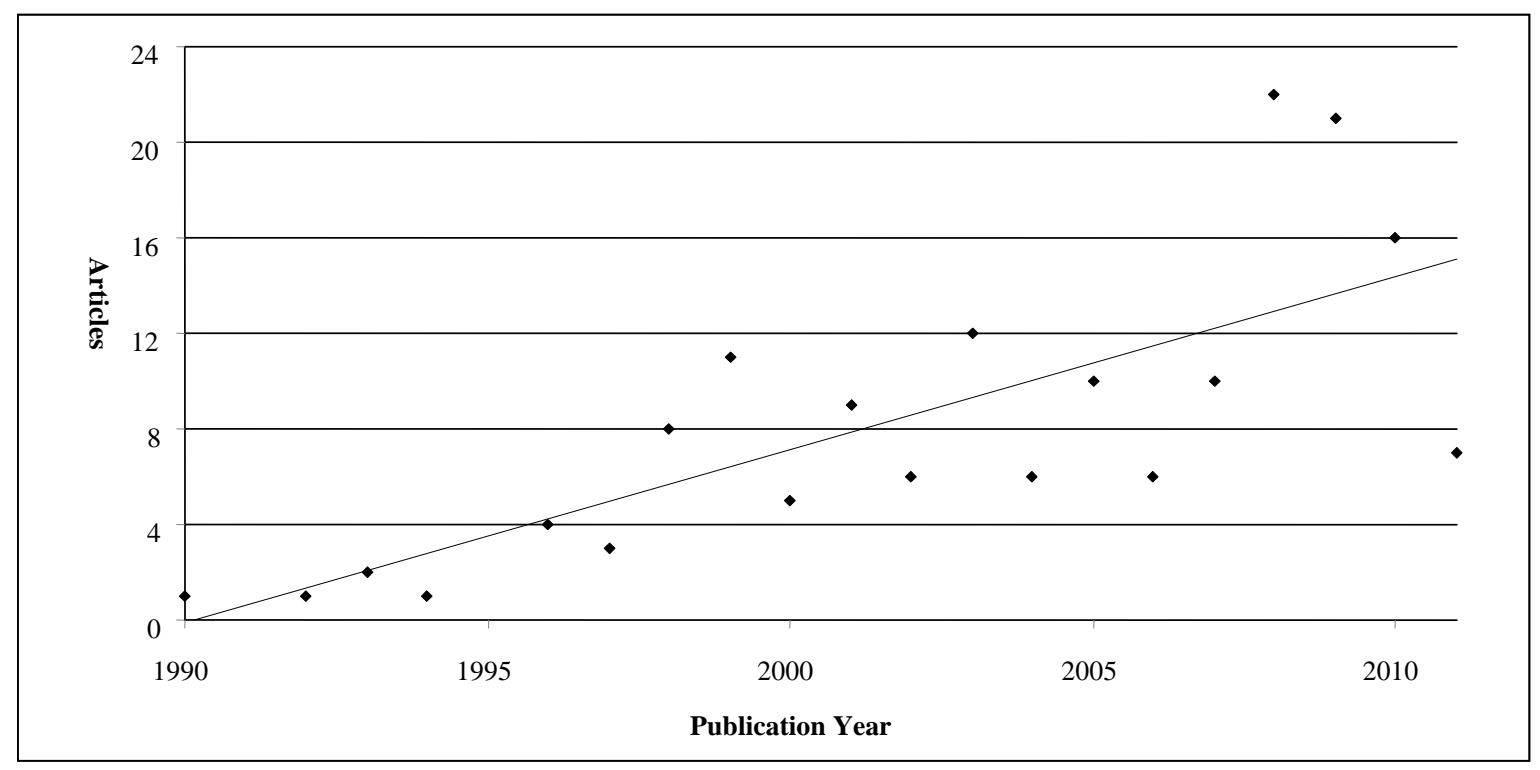

Panel B: Growth in the use of UA as a definition (diamonds and dashed trend line) and comparison (squares and dotted trend line)

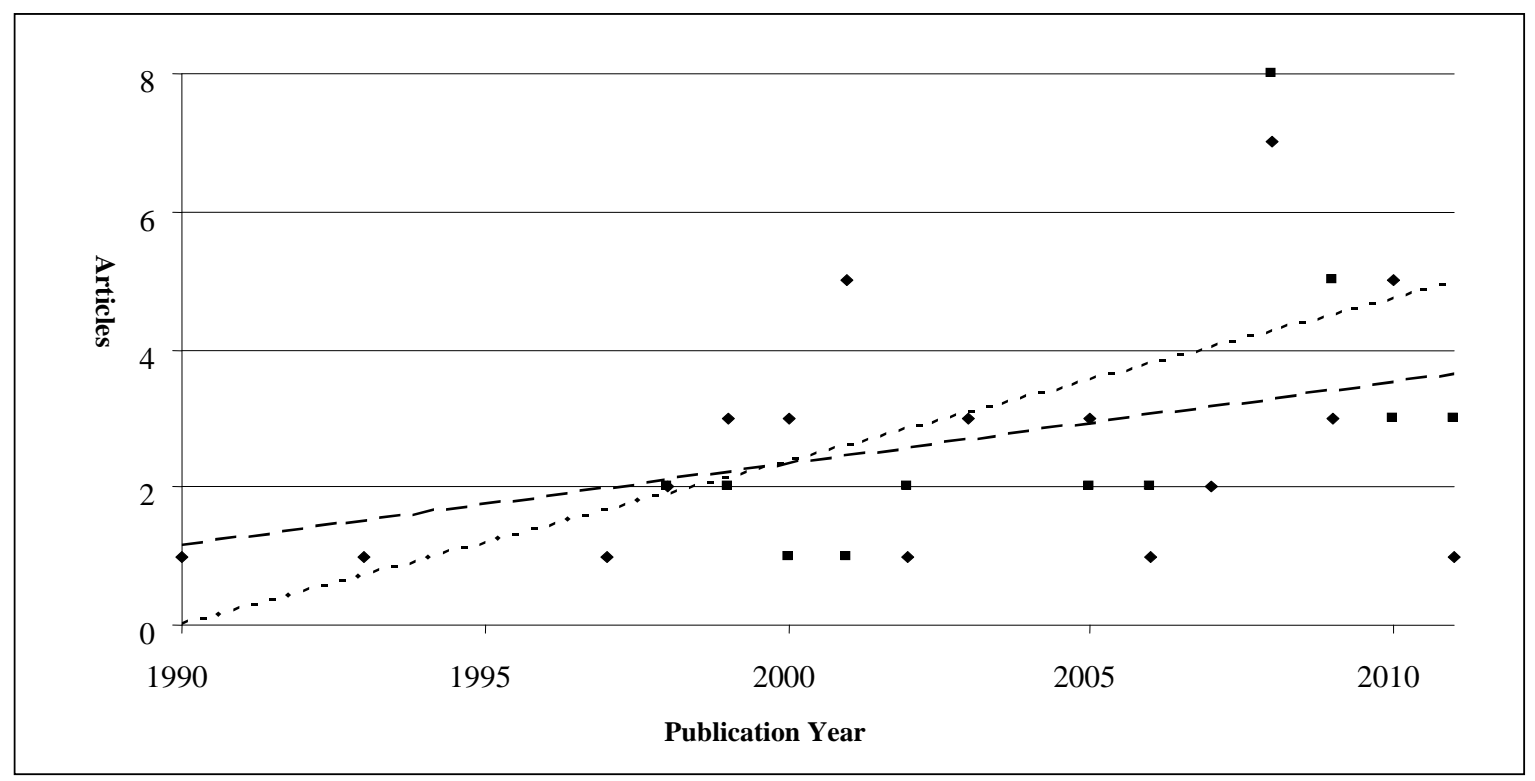

Figure 1. Number of articles using Hofstede’s UA in the Journal of Business Ethics by year 
For the 22 years of this study, we initially identified 161. Panel A of Figure 1 shows the increasing use of Hofstede's cultural dimension of uncertainty avoidance in research shown in the JoBE. Even though Hofstede's book first appeared in 1980 and cited four cultural dimensions including UA, the first article found in the JoBE that referred to Hofstede's cultural dimension of UA did not appear until 1990. There are multiple reasons for the time lag between Hofstede's first article and the first article referring to his cultural dimensions in this journal. One reason is that research at that time was not as readily accessible as it is today. In addition, there is the concern that articles before 1990 were scanned into online databases which disallow users to search articles for keywords. Since 1992, however, the average use of UA in the JoBE has increased by one article every year. A univariate regression model used the number of years since Hofstede's cultural dimension of UA was first cited in the $J o B E$ and the number of articles every year to calculate an adjusted $\mathrm{r}^{2}$ of .56 (Figure 1).

In this research, we examined the 42 articles that used UA as a definition and the 42 articles that used UA as a brief comparison. Of the 84 articles that included Hofstede's UA, 70 were in the JoBE; seven were in the $I J o V B M$; and, seven were in TBE. The trend-line data in Panel B of Figure 1 portray the growth in the use of Hofstede's UA in ethics research as a definition (dashed trend line) and as a comparison (dotted trend line).

\section{Research Findings}

\subsection{Overview}

For the 22 years of this study, we found 84 articles. Figure 1 shows the increasing use of Hofstede's cultural dimension of UA in research shown in the JoBE, IJoVBM and TBE. Even though Hofstede's book first appeared in 1980 and cited four cultural dimensions including UA, the first article found in the $J o B E$ that referred to Hofstede's cultural dimension of UA did not appear until 1990. There are multiple reasons for the time lag between Hofstede's first article and the first article referring to his cultural dimensions in this journal. One reason is that research at that time was not as readily accessible as it is today. In addition, there is the concern that articles before 1990 were scanned into online databases which disallow users to search articles for keywords. Due to the varied uses of UA, the 84 articles that included UA were categorized into two groups each with subcategories. The first group of 42 articles includes only definitional use of UA as background information. In the second group, 42 articles use UA as a brief comparison.

\subsection{Definition Articles}

Table 1 organizes 42 articles, spanning the years 1990 through 2011 that utilize a definition of UA. The number of times UA was cited briefly remained constant except for 2008, 2010 and 2011. The four panels in Table 1 show the subcategories of uses of UA. Four articles in Panel A define UA. The definitions of UA were used to explain corruption (Beets, 2005; Collins et al., 2009), management (Parnell \& Hatem, 1997) and ethics (Rawwa et al., 1998).

In Panel B, UA is defined along with other cultural dimensions. The information provided about UA, and more so, Hofstede's cultural dimensions provide a basis for understanding differences in cultures. These differences in cultural values were used to explain varied beliefs related to advertising (Lin, 2008), corruption (Chandler \& Graham, 2010), earnings management (Clikeman et al., 2001), ethics (Dunn \& Shome, 2009; Hay et al., 2001; Robertson \& Schlegelmilch, 1993), flexible work arrangements (Cohen \& Single, 2001) and justice (Primeaux et al., 2003; Sama \& Papamarcos, 2000).

Of the articles in Panel C, two articles also list Hofstede's cultural dimensions along with UA. Tang (2008) explains how UA affects people's contribution to the public well-being and Singhapakdi et al. (2001) uses UA to explain its potential effects on marketing ethics. Both articles define and list Hofstede's cultural dimensions to explain individuals' behavior within certain cultures.

Panel D contains 27 articles that list UA with Hofstede's other cultural dimensions. Thirteen articles included in Panel D listed UA with Hofstede's other cultural dimensions; the uses of UA in these articles varied. The 13 articles used the list of cultural dimensions to explain how culture can affect behaviors in several areas. Four articles (Davis et al., 1998; Nebenzahl et al., 2001; Peterson et al., 2010; Zgheib, 2005) observed the association between UA and ethics. Nine articles found relationships between UA and advertising (Fam \& Waller, 2003), business education (Lämsä et al., 2000), corruption (Schwartz, 2009), deception within the workplace (Sims, 2002), leadership (Cheung \& Chan, 2005), paternalism (Erben \& Güneșer, 2008), peer group relations (Sotto \& Kohls, 1990), regulation policy (Jing \& Graham, 2008) and whistle-blowing (MacNab \& Worthley, 2008).

Panel D includes the other uses of the UA construct. Three articles (Aygün et al., 2008; Ng \& Burke, 2010; Robertson \& Fadil, 1999) listed UA because another cultural dimension (not UA) played an integral role in the 
research and the authors found it necessary to mention the other cultural dimensions. Five articles (Chiu et al., 2008; Jin et al., 2007; Lin, 2010; Phau \& Kea, 2007; Godos-Díez et al., 2011) did not use Hofstede’s cultural dimensions in the research, but included the cultural dimensions within the limitations section of the paper. Another four articles (Jones, 1999; Kim, 2003; Singhapakdi \& Vitell, 1999; Sison, 2000) related the ability to understand countries' values to observing cultural dimensions and listed the available dimensions by which one could judge a country. UA was used differently in the final two articles. One used UA to cluster similar countries (Resick et al., 2006) and the other to reflect on previous research (Jin \& Drozdenko, 2010). The listing of UA with the other Hofstede cultural dimensions allowed researchers to explain potential differences, reflect on research limitations, understand how to evaluate countries and illustrate uses of other cultural dimensions.

Table 1. Articles Mentioning UA

\begin{tabular}{|c|c|c|c|}
\hline Author(s) & Year & Author(s) & Year \\
\hline \multicolumn{4}{|l|}{ Panel A: Defines UA } \\
\hline Beets & 2005 & Parnell \& Hatem & 1997 \\
\hline Collins et al. & 2009 & Rawwa et al. & 1998 \\
\hline \multicolumn{4}{|c|}{ Panel B: Defines UA along with other cultural dimensions } \\
\hline Chandler \& Graham & 2010 & Lin & 2008 \\
\hline Clikeman et al. & 2001 & Primeaux et al. & 2003 \\
\hline Cohen \& Single & 2001 & Robertson \& Schlegelmilch & 1993 \\
\hline Dunn \& Shome & 2009 & Sama \& Papamarcos & 2000 \\
\hline Hay et al. & 2001 & & \\
\hline \multicolumn{4}{|c|}{ Panel C: Defines UA and lists other cultural dimensions } \\
\hline Singhapakdi et al. & 2001 & & \\
\hline Tang & 2008 & & \\
\hline \multicolumn{4}{|c|}{ Panel D: Lists UA along with other cultural dimensions } \\
\hline Aygün et al. & 2008 & MacNab \& Worthley & 2008 \\
\hline Cheung \& Chan & 2005 & Nebenzahl et al. & 2001 \\
\hline Chiu et al. & 2008 & Ng \& Burke & 2010 \\
\hline Davis et al. & 1998 & Peterson et al. & 2010 \\
\hline Erben \& Güneer & 2008 & Phau \& Kea & 2007 \\
\hline Fam \& Waller & 2003 & Resick et al. & 2006 \\
\hline Godos-Díez et al. & 2011 & Robertson \& Fadil & 1999 \\
\hline Jin \& Drozdenko & 2010 & Schwartz & 2009 \\
\hline Jin et al. & 2007 & Sims & 2002 \\
\hline Jing \& Graham & 2008 & Singhapakdi \& Vitell & 1999 \\
\hline Jones & 1999 & Sison & 2000 \\
\hline Kim & 2003 & Sotto \& Kohls & 1990 \\
\hline Lämsä et al. & 2000 & Zgheib & 2005 \\
\hline Lin & 2010 & & \\
\hline
\end{tabular}

\subsection{Brief Comparison Articles}

The articles in this group provided only a brief mention of UA in a comparative study. These comparisons are separated into four subcategories in Table 2: single or multiple country studies (Panels A and B), action or belief articles (Panel C), and miscellaneous uses (Panel D). A breakdown of the number of articles in each of these three categories includes: uses of UA to compare single countries (12 articles), multiple countries (12 articles), the association of UA to another behavior (14 articles), and miscellaneous uses (four articles).

For 24 articles, UA was applied at a country level to explain actions or beliefs. The countries included in these articles vary. Panel A contains articles that focused on single country research. These included Arab societies (Sidani \& Thornberry, 2010), Arab-Gulf culture (Al-Khatib et al., 2004), China (Lowe, 1996; Tan, 2008), Egypt (Sidani \& Jamali, 2010), Iceland (Vaiman et al., 2011), India (Monga, 2007), Norway (Brinkmann, 2002), Turkey (Atakan et al., 2008), Thailand (Leung et al., 2009) and the United States (Jose \& Thibodeaux, 1999; Simga-Mugan et al., 2005). In Panel B, the articles that reviewed two countries compared Fiji to India 
(Wimalasiri, 2004), France to Russia (Chhokar et al., 2001), Germany to Turkey (Schneider et al., 2011) and Hong Kong to Taiwan (Wan et al., 2009; Whitcomb et al., 1998). In addition to those countries, the United States was compared to Egypt (Marta et al., 2003), Hong Kong (Burton et al., 2000), Mexico (Marta et al., 2008), the Netherlands (Smith \& Hume, 2005), Taiwan (Brody et al., 1999), Thailand (Singhapakdi et al., 2008) and United Kingdom (Leong et al., 2004). The articles in this section used UA to show cultural differences or to provide background information or reasoning for future discussions.

Table 2. Articles Using UA in Brief Comparisons

\begin{tabular}{|c|c|c|}
\hline Author(s) & Year & Theoretical Premise \\
\hline \multicolumn{3}{|c|}{ Panel A: One-country studies } \\
\hline Sidani \& Thornberry & 2010 & Arab Societies - Mentions previous research that stated had high UA ratings \\
\hline Al-Khatib et al. & 2004 & Arab-Gulf Culture - Mentions UA rating \\
\hline Lowe & 1996 & China - Mentions UA rating \\
\hline Tan & 2008 & China - Mentions UA rating \\
\hline Sidani \& Jamali & 2010 & Egypt - Mentions UA rating \\
\hline Vaiman et al. & 2011 & Iceland - Mentions UA rating \\
\hline Monga & 2007 & India - Uses UA to explain behaviors of Indian Managers \\
\hline Brinkmann & 2002 & Norway - Listed UA Score with other Hofstede cultural dimensions ranks \\
\hline Atakan et al. & 2008 & Turkey - Mention UA rating \\
\hline Leung et al. & 2009 & Thailand - Mentions UA rating \\
\hline Jose \& Thibodeaux & 1999 & US - Used UA to explain behaviors of American Managers \\
\hline Simga-Mugan et al. & 2005 & US - Uses UA to explain behaviors of Americans \\
\hline \multicolumn{3}{|c|}{ Panel B: Two-country studies } \\
\hline Wimalasiri & 2004 & Fiji and India - used UA to explain why they avoid risk and have measures doing so \\
\hline Chhokar et al. & 2001 & France and Russia - used UA to compare \\
\hline Schneider et al. & 2011 & Germany and Turkey - used UA to compare \\
\hline Whitcomb et al. & 1998 & Hong Kong and Taiwan - defines UA and uses UA to compare \\
\hline Wan et al. & 2009 & Hong Kong and Taiwan - suggests UA was the only major cultural difference \\
\hline Marta et al. & 2003 & US and Egypt - uses UA to compare \\
\hline Burton et al. & 2000 & US and Hong Kong - used UA to compare \\
\hline Marta et al. & 2008 & US and Mexico - mentions the UA differences \\
\hline Smith \& Hume & 2005 & US and the Netherlands - uses UA to briefly state a difference \\
\hline Brody et al. & 1999 & US and Taiwan -uses UA to compare whistle-blowing differences \\
\hline Singhapakdi, et al. & 2008 & US and Thailand - used UA to compare \\
\hline Leong et al. & 2004 & US and UK - used UA to compare \\
\hline \multicolumn{3}{|c|}{ Panel C: Uses UA as it associates with an action or belief } \\
\hline Cherry & 2006 & A positive association between UA and ethics \\
\hline Haswell et al. & 1999 & A positive association between UA and more rule specific control systems \\
\hline Li et al. & 2009 & A positive association between UA and technology uncertainty \\
\hline O’Higgins \& Kelleher & 2005 & A positive association between UA and ethics \\
\hline Preble \& Hoffman & 1999 & A positive association between $\mathrm{UA}$ and a rules orientation \\
\hline Wang \& Lin & 2009 & A positive association between UA and high brand loyalty \\
\hline Vitell et al. & 1993 & A positive association between UA and intolerance of deviations from group norms \\
\hline Moores & 2008 & A negative association between UA and software piracy - listed all cultural dimensions \\
\hline Patel \& Schaefer & 2009 & A negative association between UA and ethical decision making \\
\hline Sood & 1998 & A negative association between UA and religious factors \\
\hline Zhang et al. & 2009 & A negative association between UA and whistle-blowing in China \\
\hline Fleming et al. & 2010 & A possible association between UA and moral reasoning - listed all cultural dimensions \\
\hline Mills et al. & 2009 & A possible association between UA and Conformity. \\
\hline Sanchez et al. & 2008 & A possible association between UA and corruption \\
\hline \multicolumn{3}{|c|}{ Panel D: Miscellaneous uses of UA } \\
\hline Bowen & 2007 & Mentions UA use in comparing firms \\
\hline Insch et al. & 2008 & Uses UA \& Masculinity to relate to female expatriates \\
\hline Khatri \& Tsang & 2003 & Suggests using UA in future research \\
\hline Resick et al. & 2011 & Uses UA to compare six countries briefly \\
\hline
\end{tabular}


Associating UA with particular behaviors has become an increasingly popular research area. The associations investigated in Panel C mainly focused on ethical behaviors; however, there were several other associations between UA and behavior. Of the 14 articles in Panel C, seven of them were written in the past three years. Three of these articles focused on ethics (Cherry, 2006; O’Higgins \& Kelleher, 2005; Patel \& Schaefer, 2009), while four other articles researched similar topics such as corruption (Sanchez et al., 2008), software piracy (Moores, 2008), moral reasoning (Fleming et al., 2010) and whistle-blowing (Zhang et al., 2009). The remaining articles examined associations between UA and topics unrelated to ethics such as: brand loyalty (Wang \& Lin, 2009), conformity (Mills et al., 2009), intolerance of deviations from group norms (Vitell et al., 1993), religious factors (Sood, 1998), rules orientation (Preble \& Hoffman, 1999), rule specific control systems (Haswell et al., 1999) and technology skepticism ( $\mathrm{Li}$ et al., 2009). In addition to sorting the Panel $\mathrm{C}$ articles based on topics, there are also differences in the suggested associations between UA and other variables. Of the 14 articles that associate UA with a behavior, seven suggested positive relationships. In these studies UA had a positive association with ethics (Cherry, 2006; O’Higgins \& Kellenher, 2005), rules specific control systems (Haswell et al., 1999), technology uncertainty (Li et al., 2009), rules orientation (Preble \& Hoffman, 1999), high brand loyalty (Wang \& Lin, 2009) and intolerance of deviations from group norms (Vitell et al., 1993). In four articles, a negative association was suggested between UA and software piracy (Moores, 2008), ethical decision making (Patel \& Schaefer, 2009), religious factors (Sood, 1998) and whistle-blowing in China (Zhang et al., 2009). The authors of the last three articles in Panel C suggested an association involving UA; however, these articles did not indicate whether the associations were positive or negative. These articles discuss an association between UA and moral reasoning (Fleming et al., 2010), conformity (Mills et al., 2009) and corruption (Sanchez et al., 2008).

The four articles in Panel D are categorized as miscellaneous because they did not fit into any of the prior groups. One article suggests UA as a tool to compare firms (Bowen, 2007). Another discussed UA as it relates to female expatriates (Insch et al., 2008), the next article recommended using UA in future research (Khatri \& Tsang, 2003) and (Resick et al., 2011) briefly compared six countries including the United States, China, Germany, Hong Kong, Iceland and Taiwan.

Within Table 2, there were uses of UA in ethics research; these findings (Panel C) used UA to help create hypotheses and support beliefs within ethics research. However, none of the connections with UA and ethics research in Table 2 mirrored Hofstede's suggested relationships (Table 1). Instead, there were some articles that demonstrated an association between UA and ethics that was not mentioned by Hofstede. These authors found that high UA related to decreased perception of ethical problems (Cherry, 2006; Vitell et al., 1993), a strong emphasis on enforcement of ethical codes (Preble \& Hoffman, 1999), increased consideration of other formal codes of ethics when forming one's own code (Vitell et al., 1993), increased bribery (Moores, 2008), increased corruption (Sanchez et al., 2008) and decreased whistle-blowing (Zhang et al., 2009). In the later tables, the scope, detail and utilization of the association between UA and ethics are greater and more significant.

\section{Discussion and Conclusions}

Our research examined the extent and nature of the use of Hofstede's UA in articles published in the $J o B E$, the IJoVBM and TBE for a period of 22 years from 1990 through 2011. The beginning of this timeframe (1982) with the first issue of the $J O B E$ is two years after Hofstede's (1980) initial publication of his four cultural dimensions. While these dimensions were introduced in 1980, our data indicate that the first article to use UA in each of these three journals was: 1992 for the JoBE, 1990 for the IJoVBM and 1998 for TBE. The data in this study along with the data in Rapp et al. (2011) can be used by future researchers as a template for how Hofstede's UA construct has been used in international research both generally in a variety of business areas and specifically in various areas of business ethics research.

Our data also indicate that 42 of the 84 (50.0\%) of the articles citing Hofstede's work used the UA construct as a definition and the remaining $42(50.0 \%)$ articles used UA as a comparison when discussing cultures. This is significantly higher than the 18 articles noted by Rapp et al. (2011) in the Journal of International Business Studies. The increased use of UA in JoBE in these two categories (4.7 times higher than Rapp et al. noted) and the fact that $52.1 \%$ of the 161 articles we initially identified were in these two categories compared to only $15.7 \%$ of Rapp et al.'s articles in these categories suggests that use of UA has not developed in international ethics research to the extent it has in other areas of international research. This point offers opportunities for new research streams in international ethics research.

A limitation of our research is that it considered only articles in three ethics journals: the JoBE, the IJoVBM and TBE; of these journals, the last two have not been published since 2003. This limitation also provides the 
opportunity for future research which could examine the use of Hofstede's UA construct in other fields and topical areas to determine whether the results of this research are supported.

\section{References}

Al-Khatib, J. A., Rawwas, M. Y. A., \& Vitell, S. J. (2004). Organizational Ethics in Developing Countries: A Comparative Analysis. Journal of Business Ethics, 55(4), 309-322.

Atakan, M. G. S., Burnaz, S., \& Topcu, Y. I. (2008). An Empirical Investigation of the Ethical Perceptions of Future Managers with a Special Emphasis on Gender - Turkish Case. Journal of Business Ethics, 82(3), 573-586. http://dx.doi.org/10.1007/s10551-007-9577-z

Aygün, Z. K., Arslan, M., \& Güney, S. (2008). Work Values of Turkish and American University Students. Journal of Business Ethics, 80(2), 205-223. http://dx.doi.org/10.1007/s10551-007-9413-5

Beets, S. D. (2005). Understanding the Demand-Side Issues of International Corruption. Journal of Business Ethics, 57(1), 65-81. http://dx.doi.org/10.1007/s10551-004-3824-3

Bowen, F. (2007). Corporate Social Strategy: Competing Views from Two Theories of the Firm. Journal of Business Ethics, 75(1), 97-113. http://dx.doi.org/10.1007/s10551-006-9240-0

Brinkmann, J. (2002). Business and Marketing Ethics as Professional ethics, Concepts, Approaches and Typologies. Journal of Business Ethics, 41(1), 159-177. http://dx.doi.org/10.1023/A:1021318710382

Brody, R. G., Coulter, J. M., \& Lin, S. (1999). The Effect of National Culture on Whistle-Blowing Perceptions. Teaching Business Ethics, 3(4), 385-400. http://dx.doi.org/10.1023/A:1009895700644

Burton, B. K., Farh, J., \& Hegarty, W. H. (2000). A Cross-Cultural Comparison of Corporate Social Responsibility Orientation: Hong Kong vs. United States Students. Teaching Business Ethics, 4(2), 151-167. http://dx.doi.org/10.1023/A:1009862130160

Chandler, J. D., \& Graham, J. L. (2010). Relationship-Oriented Cultures, Corruption, and International

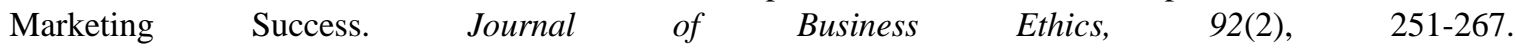
http://dx.doi.org/10.1007/s10551-009-0152-7

Cherry, J. (2006). The Impact of Normative Influence and Locus of Control on Ethical Judgments and Intentions: a Cross-Cultural Comparison. Journal of Business Ethics, 68(2), 113-132. http://dx.doi.org/10.1007/s10551-006-9043-3

Cheung, C., \& Chan, A. C. (2005). Philosophical foundations of Eminent Hong Kong Chinese CEO's Leadership. Journal of Business Ethics, 60(1), 47-62. http://dx.doi.org/10.1007/s10551-005-2366-7

Chhokar, J. S., Zhuplev, A., Fok, L. Y., \& Hartman, S. J. (2001). The Impact of Culture on Equity Sensitivity Perceptions and Organizational Citizenship Behavior: A Five-Country Study. International Journal of Value-Based Management, 14(1), 79-98. http://dx.doi.org/10.1023/A:1007865414146

Chiu, H. C., Hsieh, Y. C., \& Wang, M. C. (2008). How to Encourage Customers to Use Legal Software. Journal of Business Ethics, 80(3), 583-595. http://dx.doi.org/10.1007/s10551-007-9456-7

Clikeman, P. M., Geiger, M. A., \& O’Connell, B. T. (2001). Student Perceptions of Earnings Management: The Effects of National Origin and Gender. Teaching Business Ethics, 5(4), 389-410. http://dx.doi.org/10.1023/A:1012252922571

Cohen, J. R., \& Single, L. E. (2001). An Examination of the Perceived Impact of Flexible Work Arrangements on Professional Opportunities in Public Accounting. Journal of Business Ethics, 32(4), 317-328. http://dx.doi.org/10.1023/A:1010767521662

Collins, J. D., Uhlenbruck, K., \& Rodriguez, P. (2009). Why Firms Engage in Corruption: A Top Management Perspective. Journal of Business Ethics, 87(1), 89-108. http://dx.doi.org/10.1007/s10551-008-9872-3

Davis, M. A, Johnson, N. B., \& Ohmer, D. G. (1998). Issue-Contingent Effects on Ethical Decision Making: A Cross-Cultural Comparison. Journal of Business Ethics, 17(4), 373-389. http://dx.doi.org/10.1023/A:1005760606745

Dunn, P., \& Shome, A. (2009). Cultural Crossvergence and Social Desirability Bias: Ethical Evaluations by Chinese and Canadian Business Students. Journal of Business Ethics, 85(4), 527-543. http://dx.doi.org/10.1007/s10551-008-9787-z 
Erben, G. S., \& Güneer, A. B. (2008). The Relationship between Paternalistic Leadership and Organizational Commitment: Investigating the Role of Climate Regarding Ethics. Journal of Business Ethics, 82(4), 955-968. http://dx.doi.org/10.1007/s10551-007-9605-z

Fam, K. S., \& Waller, D. S. (2003). Advertising Controversial Products in the Asia Pacific: What Makes Them $\begin{array}{lllll}\text { Offensive. Journal of } & \text { Business }\end{array}$ http://dx.doi.org/10.1023/B:BUSI.0000005785.29778.83

Fleming, D. M., Chow, C. W., \& Su, W. (2010). An Exploratory Study of Chinese Accounting Students' and Auditors' Audit-specific Ethical Reasoning. Journal of Business Ethics, 94(3), 353-369. http://dx.doi.org/10.1007/s10551-009-0267-x

Godos-Díez, J., Fernández-Gago, R., \& Martínez-Campillo, A. (2011). How Important Are CEOs to CSR Practices? An Analysis of the Mediating Effect of the Perceived Role of Ethics and Social Responsibility. Journal of Business Ethics, 98(4), 531-548. http://dx.doi.org/10.1007/s10551-010-0609-8

Haswell, S., Jubb, P., \& Wearing, B. (1999). Accounting Students and Cheating: A Comparative Study for Australia, South Africa and the UK. Teaching Business Ethics, 3(3), 211-239. http://dx.doi.org/10.1023/A:1009830308143

Hay, D. P., Larres, M., Oyelere, P., \& Fisher, A. (2001). The Ethical Perception of Undergraduate Students in Computer-Related Situations: An Analysis of the Effects of Culture. Gender and Prior Education. Teaching Business Ethics, 5(3), 331-356. http://dx.doi.org/10.1023/A:1011445614132

Hofstede, G. (1980). Culture's Consequences: Comparing Values, Behaviors, Institutions, and Organizations across Countries. Beverly Hills, CA: Sage Publications.

Hofstede, G. (1991). Organizations and cultures: Software of the mind. New York: McGraw-Hill.

Insch, G. S., McIntyre, N., \& Napier, N. K. (2008). The Expatriate Glass Ceiling: The Second Layer of Glass. Journal of Business Ethics, 83(1), 19-28. http://dx.doi.org/10.1007/s10551-007-9649-0

Jin, K. G., \& Drozdenko, R. G. (2010). Relationships among Perceived Organizational Core Values, Corporate Social Responsibility, Ethics, and Organizational Performance Outcomes: An Empirical Study of Information Technology Professionals. Journal of Business Ethics, 92(3), 341-359. http://dx.doi.org/10.1007/s10551-009-0158-1

Jin, K. G., Drozdenko, R., \& Bassett, R. (2007). Information Technology Professionals' Perceived Organizational Values and Managerial Ethics: An Empirical Study. Journal of Business Ethics, 71(2), 149-159. http://dx.doi.org/10.1007/s10551-006-9131-4

Jing, R., \& Graham, J. L. (2008). Values Versus Regulations: How Culture Plays Its Role. Journal of Business Ethics, 80(4), 791-806. http://dx.doi.org/10.1007/s10551-007-9469-2

Jones, M. T. (1999). The Institutional Determinants of Social Responsibility. Journal of Business Ethics, 20(2), 163-179. http://dx.doi.org/10.1023/A:1005871021412

Jose, A., \& Thibodeaux, M. S. (1999). Institutionalization of Ethics: The Perspective of Managers. Journal of Business Ethics, 22(2), 133-143. http://dx.doi.org/10.1023/A:1006027423495

Khatri, N., \& Tsang, E. W. K. (2003). Antecedents and Consequences of Cronyism in Organizations. Journal of Business Ethics, 43(4), 2889-303. http://dx.doi.org/10.1023/A:1023081629529

Kim, Y. (2003). Ethical Standards and Ideology among Korean Public Relations Practitioners. Journal of Business Ethics, 42(3), 209-223. http://dx.doi.org/10.1023/A:1022281507601

Lämsä, A., Säkkinen, A., \& Turjanmaa, P. (2000). Values and Their Change during the Business Education - A Gender Perspective. International Journal of Value-Based Management, 13(3), 203-213. http://dx.doi.org/10.1023/A:1007884005732

Leong, S. M., Tan, H. H., \& Loh, M. S. (2004). When the Cat's Away: A Content Analysis of MNC Overseas Recruitment Print Ads. Journal of Business Ethics, 49(2), 115-127. http://dx.doi.org/10.1023/B:BUSI.0000015845.18419.1d

Leung, A. S. M., Liu, X., \& Liu, S. (2009). Moral Schemas and Business Practices: The Ethics of Guangzhou Migrant Marketers. Journal of Business Ethics, 88(1), 11-23. http://dx.doi.org/10.1007/s10551-008-9833-x 
Li, S., Karande, K., \& Zhou, D. (2009). The Effect of the Governance Environment on Marketing Channel Behaviors: The Diamond Industries in the U.S., China, and Hong Kong. Journal of Business Ethics, 88(3), 453-471. http://dx.doi.org/10.1007/s10551-009-0303-x

Lin, C. L. (2008). Sexual Issues: The Analysis of Female Role Portrayal Preferences in Taiwanese Print Ads. Journal of Business Ethics, 83(3), 409-418. http://dx.doi.org/10.1007/s10551-007-9628-5

Lin, C. P. (2010). Modeling Corporate Citizenship, Organizational Trust, and Work Engagement Based on Attachment Theory. Journal of Business Ethics, 94(4), 517-531. http://dx.doi.org/10.1007/s10551-009-0279-6

Lowe, S. (1996). Codes of Conduct in Hong Kong Organizations: A Preliminary Analysis. International Journal of Value-Based Management, 9(3), 211-225. http://dx.doi.org/10.1007/BF00420438

MacNab, B. R., \& Worthley, R. (2008). Self-Efficacy as an Intrapersonal Predictor for Internal Whistleblowing: A US and Canada Examination. Journal of Business Ethics, 79(4), 407-421. http://dx.doi.org/10.1007/s10551-007-9407-3

Marta, J. K. M., Attia, A., Singhapakdi, A., \& Atteya, N. (2003). A Comparison of Ethical Perceptions and Moral Philosophies of American and Egyptian Business Students. Teaching Business Ethics, 7(1), 1-20. http://dx.doi.org/10.1023/A:1022649026375

Marta, J., Heiss, C. M., \& De Lurgio, S. A. (2008). An Exploratory Comparison of Ethical Perceptions of Mexican and U.S. Marketers. Journal of Business Ethics, 82(3), 539-555. http://dx.doi.org/10.1007/s10551-007-9575-1

Mills, G. R., Austin, S. A., Thomson, D. S., \& Devine-Wright, H. (2009). Applying a Universal Content and Structure of Values in Construction Management. Journal of Business Ethics, 90(4), 473-501. http://dx.doi.org/10.1007/s10551-009-0055-7

Monga, M. (2007). Managers’ Moral Reasoning: Evidence from Large Indian Manufacturing Organizations. Journal of Business Ethics, 71(2), 179-194. http://dx.doi.org/10.1007/s10551-006-9133-2

Moores, T. (2008). An Analysis of the Impact of Economic Wealth and National Culture on the Rise and Fall of Software Piracy Rates. Journal of Business Ethics, 81(1), 39-51. http://dx.doi.org/10.1007/s10551-007-9479-0

Nebenzahl, I. D., Jaffe, E. D., \& Kavak, B. (2001). Consumers' Punishment and Rewarding Process via Purchasing Behavior. Teaching Business Ethics, 5(3), 283-305. http://dx.doi.org/10.1023/A:1011445922260

Ng, E. S., \& Burke, R. J. (2010). Predictor of Business Students' Attitudes toward Sustainable Business Practices. Journal of Business Ethics, 95(4), 603-615. http://dx.doi.org/10.1007/s10551-010-0442-0

O’Higgins, E., \& Kelleher, B. (2005). Comparative Perspectives on the Ethical Orientations of Human Resources, Marketing and Finance Functional Managers. Journal of Business Ethics, 56(3), 275-288. http://dx.doi.org/10.1007/s10551-004-3898-y

Parnell, J. A., \& Hatem, T. (1997). The Cultural Specificity of Management Constructs: An Empirical Examination. International Journal of Value-Based Management, 10(3), 247-271. http://dx.doi.org/10.1023/A:1007701229378

Patel, T., \& Schaefer, A. (2009). Making Sense of the Diversity of Ethical Decision Making in Business: An Illustration of the Indian Context. Journal of Business Ethics, 90(2), 171-186. http://dx.doi.org/10.1007/s10551-009-0034-z

Peterson, R. A., Albaum, G., Merunka, D., Munuera, J. L., \& Smith, S. M. (2010). Effects of Nationality, Gender, and Religiosity on Business-Related Ethicality. Journal of Business Ethics, 96(4), 573-587. http://dx.doi.org/10.1007/s10551-010-0485-2

Phau, I., \& Kea, G. (2007). Attitudes of University Students toward Business Ethics: A Cross-National Investigation of Australia, Singapore and Hong Kong. Journal of Business Ethics, 72(1), 61-75. http://dx.doi.org/10.1007/s10551-006-9156-8

Preble, J. F., \& Hoffman, R. C. (1999). The Nature of Ethics Codes in Franchise Associations around the Globe. Journal of Business Ethics, 18(3), 239-253. http://dx.doi.org/10.1023/A:1005733003323 
Primeaux, P. S. M., Karri, R., \& Coldwell, C. (2003). Cultural Insights to Justice: A Theoretical Perspective through a Subjective Lens. Journal of Business Ethics, 46(2), 187-199. http://dx.doi.org/10.1023/A:1025017024336

Rapp, J. K., Bernardi, R. A., \& Bosco, S. M. (2011). Examining the Use of Hofstede’s Uncertainty Avoidance Construct in International Research: A 25-Year Review. International Business Research Journal, 4(1), 3-15.

Rawwas, M. Y. A., Patzer, G. L., \& Vitell, S. J. (1998). A Cross-Cultural Investigation of the Ethical Values of Consumers: The Potential Effect of War and Civil Disruption. Journal of Business Ethics, 17(4), 373-389. http://dx.doi.org/10.1023/A:1005760606745

Resick, C. J., Hanges, P. J., Dickson, M. W., \& Mitchelson, J. K. (2006). A Cross-Cultural Examination of the Endorsement of Ethical Leadership. Journal of Business Ethics, 63(4), 345-359. http://dx.doi.org/10.1007/s10551-005-3242-1

Resick, C. J., Martin, G. S., Keating, M. A., Dickson, M. W., Kwan, H. K., \& Peng, C. (2011). What Ethical Leadership Means to Me: Asian, American, and European Perspectives. Journal of Business Ethics, 101(3), 435-457. http://dx.doi.org/10.1007/s10551-010-0730-8

Robertson, C., \& Fadil, P. A. (1999). Ethical Decision Making in Multinational Organization: A Culture-Based Model. Journal of Business Ethics, 19(4), 385-392. http://dx.doi.org/10.1023/A:1005742016867

Robertson, D. C., \& Schlegelmilch, B. B. (1993). Corporate Institutionalization of Ethics in the United States and Great Britain. Journal of Business Ethics, 12(4), 301-312. http://dx.doi.org/10.1007/BF01666534

Sama, L. M., \& Papamarcos, S. D. (2000). Hofstede's I-C Dimension as Predictive of Allocative Behaviors: A Meta-Analysis. International Journal of Value-Based Management, 13(2), 173-188. http://dx.doi.org/10.1023/A:1007838221341

Sanchez, J. I., Gomez, C., \& Wated, G. (2008). A Value-based Framework for Understanding Managerial Tolerance of Bribery in Latin America. Journal of Business Ethics, 83(2), 341-352. http://dx.doi.org/10.1007/s10551-007-9623-x

Schneider, H., Krieger, J., \& Bayraktar, A. (2011). The Impact of Intrinsic Religiosity on Consumers Ethical Beliefs: Does It Depend on the Type of Religion? A Comparison of Christian and Moslem Consumers in Germany and Turkey. Journal of Business Ethics, 102(2), 319-332. http://dx.doi.org/10.1007/s10551-011-0816-y

Schwartz, M. S. (2009). “Corporate Efforts to Tackle Corruption: An Impossible Task?” The Contribution of Thomas Dunfee. Journal of Business Ethics, 88(4), 823-832. http://dx.doi.org/10.1007/s10551-009-0318-3

Sidani, Y. M., \& Jamali, D. (2010). The Egyptian Worker: Work Beliefs and Attitudes. Journal of Business Ethics, 92(3), 433-450. http://dx.doi.org/10.1007/s10551-009-0166-1

Sidani, Y. M., \& Thornberry, J. (2010). The Current Arab Work Ethic: Antecedents, Implications, and Potential Remedies. Journal of Business Ethics, 91(1), 35-49. http://dx.doi.org/10.1007/s10551-009-0066-4

Simga-Mugan, C., Daly, B. A., Onkal, D., \& Kavut, L. (2005). The Influence of Nationality and Gender on ethical Sensitivity: An Application of the Issue-Contingent Model. Journal of Business Ethics, 57(2), 139-159. http://dx.doi.org/10.1007/s10551-004-4601-z

Sims, R. L. (2002). Support for the Use of Deception within the Work Environment: A Comparison of Israeli and United States Employee Attitudes. Journal of Business Ethics, 35(1), 27-34. http://dx.doi.org/10.1023/A:1012755801190

Singhapakdi, A., \& Vitell, S. J. (1999). From the Guest Editors International Marketing Editors. Journal of Business Ethics, 18(1), 1-2. http://dx.doi.org/10.1023/A:1006096822309

Singhapakdi, A., Gopinath, M., Marta, J. K., \& Carter, L. L. (2008). Antecedents and Consequences of Perceived Importance of Ethics in Marketing Situations: A Study of Thai Businesspeople. Journal of Business Ethics, 81(4), 887-904. http://dx.doi.org/10.1007/s10551-007-9555-5

Singhapakdi, A., Marta, J. K. M., Rao, C. P., \& Cicic, M. (2001). Is Cross-Cultural Similarity an Indicator of Similar Marketing Ethics. Journal of Business Ethics, 32(1), 55-68. http://dx.doi.org/10.1023/A:1010699529874 
Sison, A. J. G. (2000). The Cultural Dimension of Codes of Corporate Governance: A Focus on the Olivencia Report. Journal of Business Ethics, 27(1), 181-192. http://dx.doi.org/10.1023/A:1006474706790

Smith, A., \& Hume, E. C. (2005). Linking Culture and Ethics: A Comparison of Accountants' Ethical Belief Systems in the Individualism/Collectivism and Power Distance Contexts. Journal of Business Ethics, 62(30), 209-220. http://dx.doi.org/10.1007/s10551-005-4773-1

Sood, J. (1998). A Cross-Cultural Study of Value Emphasized in Education. International Journal of Value-Based Management, 11(3), 215-223. http://dx.doi.org/10.1023/A:1007787007464

Sotto, F. C., \& Kohls, J. J. (1990). White-Collar Work Values and Attitudes: A Cross-Cultural Comparison of the U.S. and the Philippines. International Journal of Value-Based Management, 3(2), 21-35. http://dx.doi.org/10.1007/BF01732411

Tan, J. (2008). Breaking the 'Bamboo Curtain' and the 'Glass Ceiling': The Experience of Women Entrepreneurs in High-Tech Industries in an Emerging Market. Journal of Business Ethics, 80(3), 547-564. http://dx.doi.org/10.1007/s10551-007-9454-9

Tang, L. (2008). An Integral Model of Collective Action in Organizations and Beyond. Journal of Business Ethics, 80(2), 249-261. http://dx.doi.org/10.1007/s10551-007-9416-2

Vaiman, V., Sigurjonsson, T. O., \& Davídson, P. A. (2011). Weak Business Culture as an Antecedent of Economic Crisis: The Case of Iceland. Journal of Business Ethics, 98(2), 259-272. http://dx.doi.org/10.1007/s10551-010-0546-6

Vitell, S. J., Nwachukwu, S. L., \& Barnes, J. H. (1993). The Effects of Culture on Ethical Decision-Making: An Application of Hofstede's Typology. Journal of Business Ethics, 12(10), 753-760. http://dx.doi.org/10.1007/BF00881307

Wan, W. W., Luk, C. L., Yau, O. H., Tse, A. C., Sin, L. Y., Kwong, K. K., \& Chow, R. P. (2009). Do Traditional Chinese Cultural Values Nourish a Market for Pirated CDs. Journal of Business Ethics, 88(1), 185-196. http://dx.doi.org/10.1007/s10551-008-9821-1

Wang, C. L., \& Lin, X. (2009). Migration of Chinese Consumption Values: Traditions, Modernization, and Cultural Renaissance. Journal of Business Ethics, 88(3) 399-409. http://dx.doi.org/10.1007/s10551-009-0308-5

Whitcomb, L. L., Erdener, C. B., \& Li, C. (1998). Business Ethical Values in China and the U.S.. Journal of Business Ethics, 17(8), 839-852.

Wimalasiri, J. S. (2004). Contrasts in Moral Reasoning Capacity: The Fijians and the Singaporeans. Journal of Business Ethics, 49(3), 251-272. http://dx.doi.org/10.1023/B:BUSI.0000017970.17717.8c

Zgheib, P. W. (2005). Managerial Ethics: An Empirical Study of Business Students in the American University of Beirut. Journal of Business Ethics, 61(1), 69-78. http://dx.doi.org/10.1007/s10551-004-6394-5

Zhang, J., Chiu, R., \& Wei, L. (2009). Decision-Making Process of Internal Whistleblowing Behavior in China: Empirical Evidence and Implication. Journal of Business Ethics, 88(1), 25-41. http://dx.doi.org/10.1007/s10551-008-9831-z 